\title{
Effect of Atorvastatin on Acute Pancreatitis in Rat:A Biochemical and Pathological Study
}

\author{
Maedeh Ghorbani ${ }^{1}$, Mehdi Chavoshi-Nejad ${ }^{2}$, Tina Parsa ${ }^{3}$, Sara Ershadi ${ }^{4}$, Abolfazl Saadat Eskandari ${ }^{4}$, Ahmad Berimipo- \\ $u^{4}$, Mohammad Baghery Bidhendy ${ }^{4}$, Soheila Yadollah-Damavandi ${ }^{3 凶}$

\footnotetext{
${ }^{1}$ Department of Surgery, Islamic Azad University, Tehran Medical Sciences Branch, Tehran, Iran

${ }^{2}$ Department of Surgery, Shahid Beheshti University of Medical Sciences, Tehran, Iran.

${ }^{4}$ Students' Research Committee, Islamic Azad University, Tehran Medical Sciences Branch, Tehran, Iran.
} \\ ${ }^{3}$ Young Researchers and Elite Club, Islamic Azad University, Tehran Medical Sciences Branch, Tehran, Iran.
}

\section{Dear Editor,}

A cute pancreatitis (AP) is a common clinical disease caused mainly by gallstone impacting distal common bile-pancreatic duct and alcohol abuse, but other potential causes like Endoscopic retrograde cholangiopancreatography (ERCP), intra duct papillary mucinous tumor and hypercalcemia are claimed [1]. Incidence of AP has been increasing in recent years [2]. Accordingly, AP is a multifactorial disease associated with tissue edema, acinar necrosis, hemorrhage and release of digestive enzymes to pancreatic interstitium and to systemic circulation with increased cytokine production and release, which can ultimately lead to deleterious local and systemic effects [3]. Previous evidence suggests that the pathogenesis of both AP and chronic pancreatitis could be associated with oxidative stress, regardless of the etiology of pancreatitis. It is considered as a major pathogenic factor in AP [4]. In fact, reactive oxygen species (ROS) are important mediators in the initiation and development of this disease destroying cellular membrane, releasing digestive enzymes and cellular proteins into the pancreatic interstitium [5].

HMG-CoA reductase is the enzyme that catalyses the conversion of HMG-CoA in mevalonate and this is the limiting step in cho-

\section{GMJ}

2013 Galen Medical Journal

Fax: +98 7312227091

PO Box 7461686688

Email:info@gmj.ir lesterol synthesis. Atorvastatin is an HMGCoA reductase inhibitor used clinically in the treatment of hyperlipidemia [6]. In addition to their antihyperlipidemic effect, statins have antioxidant activity against lipid peroxidation, anti-inflammatory effects, induce nitric oxide levels, impeding thrombogenesis by inhibiting activation of extrinsic coagulation, produce beneficial effects in hypertension, improving endothelial dysfunction, and provide additional cardioprotective effects [7]. Hence, the present study is aimed to determine the protective effects of Atorvastatin against AP. In this study, 36 Sprague Dawley rats (200$250 \mathrm{gr})$ were divided into 3 groups $(\mathrm{n}=8)$ : control group which received intraperitoneal (i.p) injections of normal saline. In sham and experimental groups, pancreatitis was induced which $3.2 \mathrm{~g} / \mathrm{kg}$ body weight L-arginine (Sigma-Aldrich, Germany) i.p. twice at an interval of $1 \mathrm{~h}$. Rats in experimental group were treated with a single dose of $40 \mathrm{mg} / \mathrm{kg}$ body weight Atorvastatin (Sigma-Aldrich, Germany) i.p. $30 \mathrm{~min}$ prior to L-arginine administration. All rats were sacrificed at $24 \mathrm{~h}$ after the last L-arginine injection, and blood from angular vein as well as pancreatic tissue was harvested for study. The levels of serum amylase, lipase, pancreas malondialdehyd (MDA)

\footnotetext{
Correspondence to:

Soheila Yadollah-Damavandi,Medical Research

Center, Azad University, Tehran Medical Branch,

Attarimoqaddam Ave, Haqani Ave, Dr. Shariati St, Tehran, Iran.

Telephone Number: (+98)21 22006660

Email Address: soheila_d69@yahoo.com
} 
and myeloperoxidase (MPO) were assayed by using clinical test kits (Abcam, USA). Acinar cell injury/necrosis were assessed and scored by an expert blinded pathologist according to the method reported by Babu et al [8]. Mann-Whitney U-test was used for statistical analysis and all tests were done via SPSS statistical software (16, USA). P value $\leq 0.05$ was considered statistically significant.

Concentrations of pancreas enzymes, MDA and MPO are shown in Table 1. Study results indicated no significant difference between experimental group and control group concerning pancreas enzymes (amylase and lipase), pancreas MPO and MDA levels. Nevertheless, a significant difference was observed between experimental group and sham group in this regard $(\mathrm{P}<0.05)$. Histopathological examinations of pancreas also described lower grades of injury/necrosis in the experimental group compared to the sham group which both were in severe grades predominantly (Figure1).

Previous studies demonstrated therapeutic effects of Atorvastatin on metabolic stress by inhibition of apoptosis in hepatocytes [9, 10]. Moreover, it was revealed that Atorvastatin through its antioxidant, anti-inflammatory, and anti-apoptotic effects could have a role in the improvement of L-arginine-induced toxicity. Few case reports have reported acute pancreatitis due to treatment with Atorvastatin, Fluvastatin, Lovastatin and Simvastatin. However, few studies exist on the incidence of drug-induced pancreatitis in general population [11]. In this study, administration of Atorvastatin showed its beneficial effects in rat acute pancreatitis model, which may exert an anti-inflammatory effect and reduce histological damage due to its ability to regulate the production of oxidative stress and to cause MPO and MDA to revert to control levels. Finally, considering results of the present study and previous reports on Stations, this agent can be further evaluated for its positive impacts on the patients suffering from AP diseases. It may possibly be used as a supplement in order to attenuate toxin-induced complications.

Table 1. Effect of Atorvastatin on Pancreas Enzymes (Amylase and Lipase), MPO and MDA Levels in Rats. Data was presented as Mean \pm SD.

\begin{tabular}{|c|c|c|c|c|}
\hline & Amylase $\mathbf{U} / \mathbf{L}$ & Lipase $\mathrm{U} / \mathrm{L}$ & MDA nmol/mg & MPO U/mg \\
\hline Control & $107.3 \pm 0.6$ & $47.7 \pm 1.5$ & $11.3 \pm 1.4$ & $0.03 \pm 0.001$ \\
\hline Sham & $151.4 \pm 3.1^{\mathrm{a}}$ & $117.1 \pm 2.4^{\mathrm{a}}$ & $27.1 \pm 2.6^{\mathrm{a}}$ & $0.28 \pm 0.001^{\mathrm{a}}$ \\
\hline Experimental & $123.9 \pm .1 .3^{\mathrm{b}}$ & $88.4 \pm 2.7 b$ & $18.9 \pm 0.7^{\mathrm{b}}$ & $0.15 \pm 0.002^{\mathrm{b}}$ \\
\hline
\end{tabular}

${ }^{a} \mathrm{P} \leq 0.05$ versus control group

${ }^{\mathrm{b}} \mathrm{P} \leq 0.05$ versus sham group
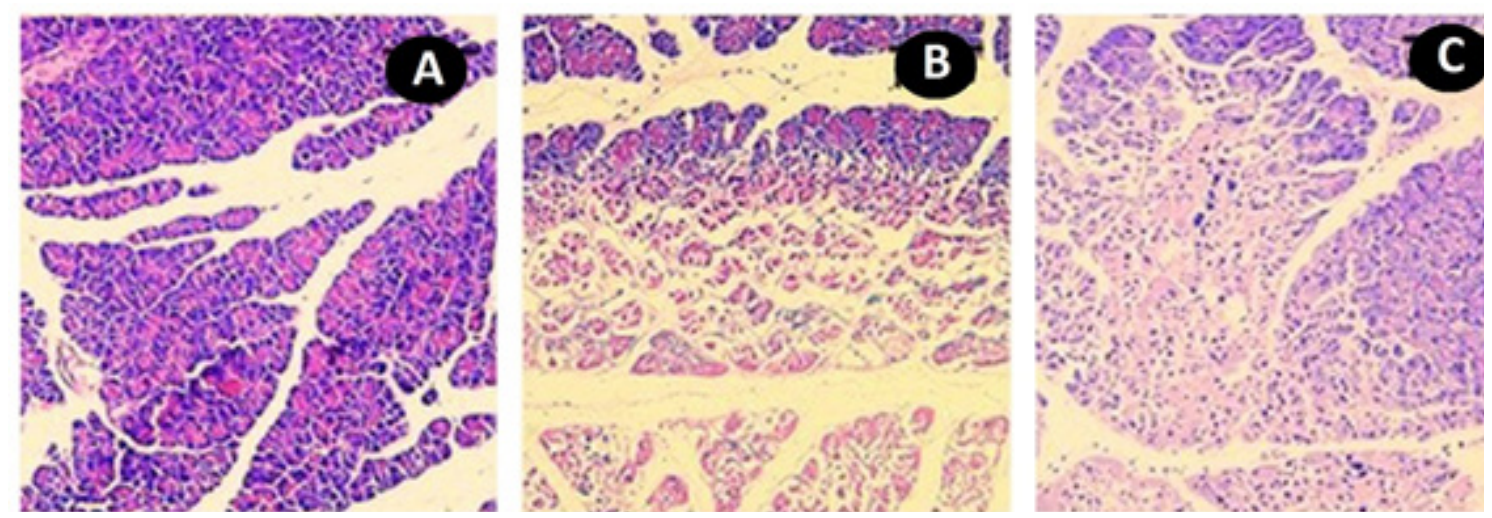

Figure1. Microscopic Images of Pancreas in Rats. (Hematoxylin-eosin stain, × 200). A: Normal Pancreas in Control Group. B: Severe edema, inflammation and acinar necrosis were noted in the sham group. C: In the experimental group, Atorvastatin reduced pancreatic edema, inflammation and acinar necrosis. 


\section{References}

1. Wang GJ, Gao CF, Dong Wei, Wang C and Ding SQ. Acute pancreatitis: Etiology and common pathogenesis. World J Gastroenterol. 2009;15(12):1427-30.

2. Yadav D and Lowenfels AB. Trends in the epidemiology of the first attack of acute pancreatitis: a systematic review. 2006;33(4):32330.

3. Tsang SW, IP SP, Wong TP, Che CT and Leung PS. Differential effects of saralasin and amiprilat, the inhibitors of renin-angiotensin system, on cerulein-induced acute pancreatitis. Regul Pept. 2003;111(1-3):47-53

4. Valko M, Leibfritz D, Moncol J, Cronin MT, Mazur M, Telser J. Free radicals and antioxidants in normal physiological functions and human disease. Int $\mathrm{J}$ Biochem Cell Biol. 2007;39(1): 44-84.

5. Armstrong J, Cash N, Soares P, Souza M, Sutton R, Criddle D. Oxidative stress in acute pancreatitis: lost in translation? Free Radic Res. 2013;47(11):917-33.

6. Almeida J, Sampietre S, Mendonça CA, Trindade MN, Machado M, Monteiro dCJ, et al. Statin pretreatment in experimental acute pancreatitis. JOP. 2008;9(4):431-9.
7. Tandon V, Gupta B, Tandon R. Non-lipids actions of statins. JK Science. 2004;6:124-126.

8. Babu B, Malleo G, Genovese T, Mazzon E, Di Paola R, Crisafulli C, et al. Green tea polyphenols ameliorate pancreatic injury in cerulein-induced murine acute pancreatitis. Pancreas. 2009;38(8):954-67.

9. Mäuser W, Perwitz N, Meier B, Fasshauer M, Klein J. Direct adipotropic actions of atorvastatin: differentiation state-dependent induction of apoptosis, modulation of endocrine function, and inhibition of glucose uptake. Eur J Pharmacol. 2007;564(1-3):37-46.

10. Gürpınar T, Ekerbiçer N, Uysal N, Barut T, Tarakçı F, Tuğlu M. The histologic evaluation of atorvastatin and melatonin treatment on oxidative stress and apoptosis of diabetic rat pancreas. Kafkas Üniversitesi Veteriner Fakültesi Dergisi. 2010;16(4):547-52.

11. Anagnostopoulos G, Tsiakos S, Margantinis G, Kostopoulos P, Arvanitidis D. Acute pancreatitis due to pravastatin therapy. JOP. 2003;4(3):129-32. 